\title{
Fibrous Dysplasia of the Craniofacial Bones
}

Wen-Sen Lai, MD

Jih-Chin Lee, MD

From the Department of Otorhinolaryngology- Head and Neck Surgery, TriService General Hospital National Defense Medical Center in Taipei, Taiwan. Dr Lai is also associated

with the Department of Otolaryngology-Head and

Neck Surgery, Taichung

Armed Forces General Hospital in Taichung, Taiwan.

Financial Disclosures:

None reported.

Address correspondence to Jih-Chin Lee, MD, Department of

OtorhinolaryngologyHead and Neck Surgery, Tri-Service General Hospital,

No 325 , Sec 2 , Chenggong Rd,

Neihu District, Taipei City 114, Taiwan (Republic of China).

$$
\begin{array}{r}
\text { E-mail: } \\
\text { doc30450@gmail.com } \\
\text { Submitted } \\
\text { November 28, 2012; } \\
\text { final revision received } \\
\text { January 7, 2013; } \\
\text { accepted } \\
\text { January 23, } 2013 .
\end{array}
$$

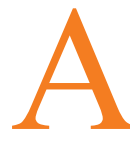

n elderly woman presented with a history of slow and progressive facial asymmetry since childhood. Physical examination revealed painless right facial enlargement involving the soft tissue and bony structures of the maxilla and mandible (image A). A plain radiograph revealed hazy radiopacities with a ground glass appearance (image B), suggestive of polyostotic fibrous dysplasia (FD). Transoral excisional biopsy revealed fibrous stroma in which spicules of disconnected woven bone were noted, confirming the diagnosis of polyostotic FD. The patient was treated with $70 \mathrm{mg}$ of alendronate once weekly to improve bone density, decrease the diameter of the lesion, and decrease pain scores. At 30-month follow-up, no other complaints were reported, and the craniofacial FD was smaller.

Craniofacial FD masses are almost exclusively unilateral; the maxilla and mandible are most frequently affected followed by the frontal, parietal, and occipital bones. ${ }^{1}$ Although approximately $1 \%$ of craniofacial FD cases carry a risk of malignant transformation, it typically follows a benign and indolent course of bone malformation. ${ }^{2}$ Bisphosphonate therapy may be useful in treating patients for refractory pain. Immediate surgical care may be necessary for patients with rapid growth, new sensory changes, or auditory or visual disturbances. ${ }^{3}$ (doi:10.7556/jaoa.2013.027)

\section{References}

1. Wei YT, Jiang S, Cen Y. Fibrous dysplasia of skull. J Craniofac Surg. 2010;21(2):538-542. doi:10.1097 /SCS.0b013e3181d0243f.

2. Leet AI, Collins MT. Current approach to fibrous dysplasia of bone and McCune-Albright syndrome. J Child Orthop. 2007;1(1):3-17. doi:10.1007/s11832-007-0006-8.

3. Lee JS, Fitzgibbon EJ, Chen YR, et al. Clinical guidelines for the management of craniofacial fibrous dysplasia. Orphanet J Rare Dis. 2012;7(suppl 1):S2. doi:10.1186 /1750-1172-7-S1-S2.

\section{(C) 2013 American Osteopathic Association}
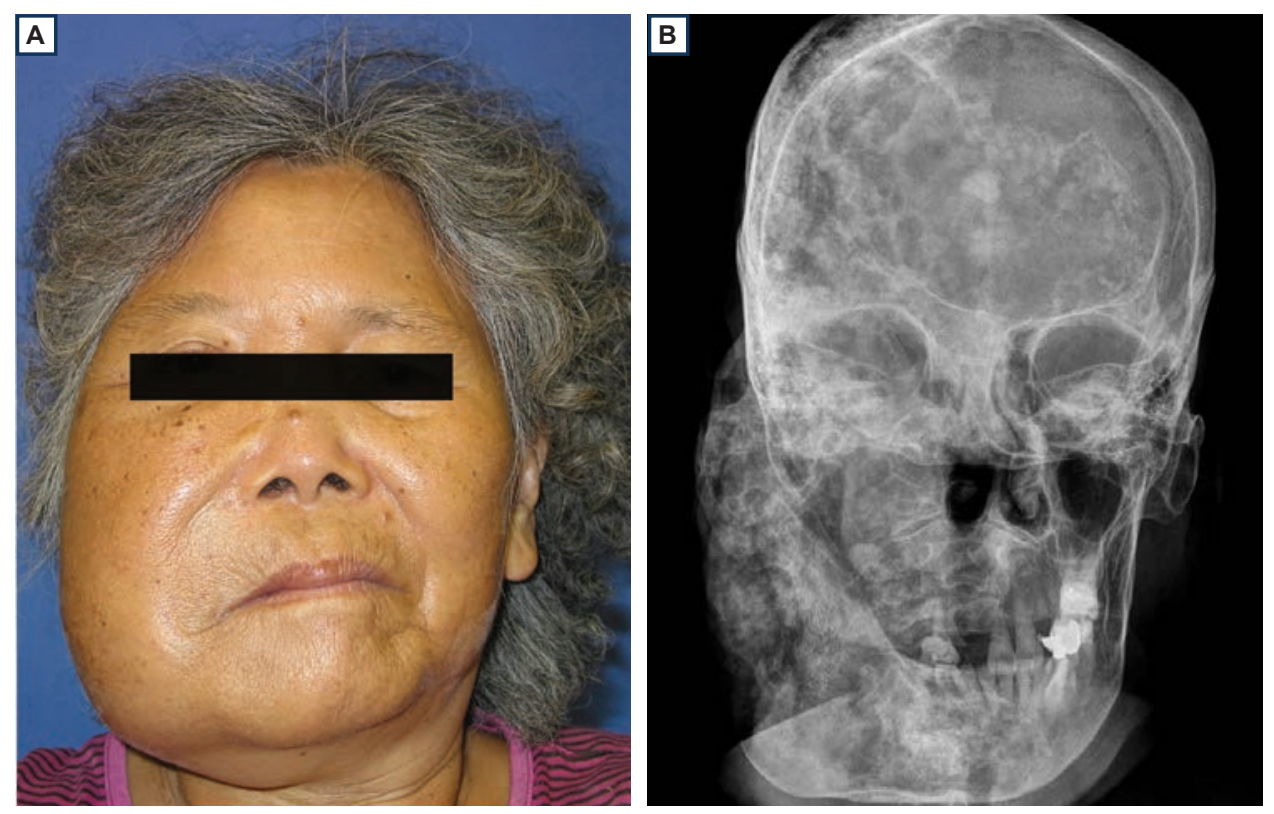